\title{
HIF-1 $\alpha$ stabilization by mitochondrial ROS promotes Met-dependent invasive growth and vasculogenic mimicry in melanoma cells
}

\author{
Giuseppina Comito a , Maura Calvani a , Elisa Giannoni a , Francesca Bianchini ${ }^{\text {b }}$, Lido Calorini ${ }^{\text {b,c }}$, \\ Eugenio Torre $^{\mathrm{b}}$, Cristina Migliore ${ }^{\mathrm{d}}$, Silvia Giordano ${ }^{\mathrm{d}}$, Paola Chiarugi a,c,* \\ a Department of Biochemical Sciences, University of Florence, 50134 Firenze, Italy \\ b Department of Experimental Pathology and Oncology, University of Florence, 50134 Firenze, Italy \\ c Istituto Toscano Tumori and Center for Research, Transfer, and High Education DenoTHE, 50134 Firenze, Italy \\ ${ }^{\mathrm{d}}$ Institute for Cancer Research and Treatment, University of Torino School of Medicine, Candiolo, Torino, Italy
}

\section{A R T I C L E I N F O}

\section{Article history:}

Received 17 January 2011

Revised 9 May 2011

Accepted 31 May 2011

Available online 12 June 2011

\section{Keywords:}

Reactive oxygen species

Melanoma

Hypoxia

Met

Invasiveness

Free radicals

\begin{abstract}
A B S T R A C T
The "angiogenic switch" during tumor progression is increasingly recognized as a milestone event in tumorigenesis, although the surprising prometastatic effect of antiangiogenic therapies has recently shaken the scientific community. Tumor hypoxia has been singled out as a possible responsible factor in this prometastatic effect, although the molecular pathways are completely unknown. We report herein that human melanoma cells respond to hypoxia through a deregulation of the mitochondrial release of reactive oxygen species (ROS) by the electron transfer chain complex III. These ROS are mandatory to stabilize hypoxia-inducible factor-1 $\alpha($ HIF-1 $\alpha)$, the master transcriptional regulator of the hypoxic response. We found that melanoma cells sense hypoxia-enhancing expression/activation of the Met proto-oncogene, which drives a motogenic escape program. Silencing analyses revealed a definite hierarchy of this process, in which mitochondrial ROS drive HIF$1 \alpha$ stabilization, which in turn activates the Met proto-oncogene. This pathway elicits a clear metastatic program of melanoma cells, enhancing spreading on extracellular matrix, motility, and invasion of 3D matrices, as well as growth of metastatic colonies and the ability to form capillary-like structures by vasculogenic mimicry. Both pharmacological and genetic interference with mitochondrial ROS delivery or Met expression block the hypoxiadriven metastatic program. Hence, we propose that hypoxia-driven ROS act as a primary driving force to elicit an invasive program exploited by aggressive melanoma cells to escape from a hypoxic hostile environment.
\end{abstract}

(c) 2011 Elsevier Inc. All rights reserved.
More than $50 \%$ of locally advanced solid tumors, including melanoma, are characterized by hypoxic areas originating from an imbalance between oxygen supply and expenditure in the actively proliferating tumor cells [1]. Oxygen supply is further worsened by an inadequate tumor vasculature until de novo angiogenesis is induced $[2,3]$. The presence of hypoxic areas within a tumor mass is invariably a poor prognosis marker for patients with a range of cancer types, including aggressive melanoma [4]. Furthermore, the failure of overall survival benefit due to increased metastatic dissemination after antiangiogenic therapies suggests that hypoxia may cooperate with endothelial inflammation for metastasis spread [5-7].

Metastasis is a multistep route in which cancer cells should gain motile features, become able to degrade the extracellular matrix (ECM),

Abbreviations: ECM, extracellular matrix; H\&E, hematoxylin and eosin; HGF, hepatocyte growth factor; HIF, hypoxia-inducible factor; NAC, $\mathrm{N}$-acetylcysteine; PDGF, platelet-derived growth factor; PHD, prolyl hydroxylase; ROS, reactive oxygen species; VEGF, vascular endothelial growth factor.

* Corresponding author at: Department of Biochemical Sciences, University of Florence, 50134 Firenze, Italy. Fax: + 390554598905.

E-mail address: paola.chiarugi@unifi.it (P. Chiarugi) and enter the blood and lymphatic vessels. Metastatic cells should then survive to anoikis, while being without a proper ECM attachment, elude immunosurveillance, home to target distant sites, and finally grow in the new environment [8]. Tumor hypoxia can affect most of these steps, indeed: (i) it activates a glycolytic metabolism of tumors cells, thereby allowing survival within the hypoxic environment; (ii) it increases invasion by regulating the transition toward a mesenchymal phenotype (the so-called epithelial-mesenchymal transition), by promoting the degradation and remodeling of the ECM through increased production of urokinase-type plasminogen activator receptor and metalloproteinase-2 $[9,10]$, as well as by regulating motogenic growth factor receptors such as hepatocyte growth factor receptor (HGF)/Met [11]; (iii) tumor hypoxia contributes to tumor angiogenesis via induction of proangiogenic factors such as vascular endothelial growth factor (VEGF) or interleukin-8 and angiopoietin-2 [12,13]; (iv) hypoxia also increases resistance to anoikis by suppression of $\alpha 5$ integrin [14]; and (v) finally, by increasing the expression of lysyl oxidase, hypoxia prepares a receptive environment for metastatic cells through the recruitment to the metastatic niche of bone marrow-derived cells [15].

The hypoxia-inducible factors (HIFs) mediate transcriptional responses to changes in oxygen levels by activating the transcription 
of hundreds of target genes $[3,16]$. HIF-1 is a heterodimeric protein composed of HIF- $1 \alpha$ and HIF- $1 \beta$ subunits, belonging to the basic helix-loop-helix superfamily of transcription factors. The HIF- $1 \alpha$ subunit is subjected to $\mathrm{O}_{2}$-dependent asparaginyl and prolyl hydroxylation, leading respectively to loss of transcriptional activity or binding to von Hippel-Landau ubiquitin ligase and proteasomal degradation of HIF-1 $\alpha$. Under hypoxic conditions, the hydroxylation reactions are inhibited, and HIF- $1 \alpha$ is stabilized and competent to activate transcription of target genes. Among the first HIF-1 target genes to be identified were the human VEGF gene, several glycolytic enzymes, and several motility factors and their receptors.

Recent data implicate mitochondrial ROS production observed in mild hypoxia $\left(1-3 \% \mathrm{O}_{2}\right)$ in HIF- $1 \alpha$ stabilization. In contrast to expectation, limited oxygen increases mitochondrial ROS rather than diminishing them $[17,18]$. ROS, in turn, inactivate prolyl hydroxylases (PHDs), through oxidation of the ferrous ion that is essential for their catalytic mechanism, and hence stabilize HIF- $1 \alpha$. Vitamin $C$ has been shown to decrease HIF-1 levels by preventing the oxidation of the catalytic ferrous ion $[18,19]$. In keeping with this, it has been recently reported that the antitumorigenic effect of antioxidants as $\mathrm{N}$-acetylcysteine (NAC) and vitamin $\mathrm{C}$ in murine models of Myc-mediated tumorigenesis are indeed HIF-1-dependent [20].

Hypoxia has now received attention in the progression of aggressive melanoma. HIF-1 plays a critical role in uveal melanoma by increasing the expression of a number of target genes involved in invasion [21] and is currently considered one of the critical biomarkers predicting liver metastasis [22]. Furthermore, a recent study by Qi and colleagues [23] supports a role in melanoma development and metastasis of Siah2, a ubiquitin ligase that regulates PHDs, leading to a stabilization of HIF- $1 \alpha$ under hypoxic conditions. Moreover, HIF- $1 \alpha$ expression in melanoma samples has been associated with poor overall disease survival [24]. Hypoxia has been additionally linked to vasculogenic mimicry of B16 mouse melanoma, thereby suggesting a facilitation of blood supply and metastasis dissemination [25].

Although these observations strongly suggest a role for hypoxia and HIF signaling in melanoma progression, the mechanistic aspect of hypoxia/HIF-mediated melanoma progression still remains relatively unexplored. We report herein that in Hs29-4T human melanoma cells hypoxia leads to a redox-dependent stabilization of HIF- $1 \alpha$, mainly mediated by mitochondrial ROS. This in turn leads to increased expression and activation of the proto-oncogene Met and to activation of the motogenic and invasive program of melanoma cells. Elimination of mitochondrial ROS production during hypoxia leads to a strong decrease in melanoma cell invasiveness and lung experimental metastasis formation.

\section{Material and methods}

\section{Materials}

Unless specified all reagents were obtained from Sigma. Hs29-4T cells were from the ATCC, all antibodies were from Santa Cruz Biotechnology, except for the anti-HIF-1 $\alpha$, which was from BD Biosciences. 2',7'-Dichlorofluorescein diacetate (DCF-DA) was from Molecular Probes and the ATP-competitive inhibitor of Met kinase PHA-665752 (PHA) was from Tocris. Polyvinylidene difluoride was from Millipore and Matrigel was from BD Biosciences. siRNA oligonucleotides targeting HIF-1 $\alpha$ (target sequence 5'-AAAGGACAAGUCACCACAGGA-3') and siRNA targeting the Rieske iron-sulfur protein (target sequence 5'-AAUGCCGUCACCCAGUUCGUU-3') were obtained from Qiagen.

\section{Cell culture and transfections}

Hs29-4T cells were cultured in Dulbecco's modified Eagle's medium supplemented with $10 \%$ fetal calf serum, in a $10 \% \mathrm{CO}_{2}$ humidified atmo- sphere. Experiments under hypoxic conditions $\left(1 \% \mathrm{O}_{2}\right)$ were performed in the hypoxic incubator. For transient transfections, Hs29-4T cells were plated in $60-\mathrm{mm}$ cell culture dishes and grown to $80 \%$ confluence. The siRNA was diluted to a final concentration of $20 \mathrm{nM}$. Transfections were performed using Lipofectamine (Invitrogen), following the manufacturer's recommendations, $48 \mathrm{~h}$ before treatment with the indicated conditions. See Supplementary Fig. 1 for immunoblot analysis.

\section{In vitro migration and invasiveness assays}

Hs29-4T cell invasion was assayed with the Transwell system of Costar, equipped with 8 - $\mu \mathrm{m}$ pore-size polyvinylpyrrolidone-free polycarbonate filters (diameter, $13 \mathrm{~mm}$ ). Migration or invasiveness assays are distinguished by the absence (migration assay) or the presence (invasiveness assay) of a 3D barrier of Matrigel. Matrigel (BD Biosciences) was diluted ( $30 \mu \mathrm{g}$ in $100 \mu \mathrm{l}$ of $\mathrm{H}_{2} \mathrm{O}$ ), added to the top chamber, allowed to solidify for $1 \mathrm{~h}$ at $37^{\circ} \mathrm{C}$, and air dried for $16 \mathrm{~h}$. The Matrigel barrier was reconstituted with $100 \mu$ of Dulbecco's modified Eagle's medium for $2 \mathrm{~h}$ at $37^{\circ} \mathrm{C}$ before use. Cells were loaded into the upper compartment $\left(5 \times 10^{4}\right.$ cells in $\left.300 \mu \mathrm{l}\right)$ in serum-deprived growth medium. The Matrigel invasion chambers were placed into six-well culture dishes containing $500 \mu \mathrm{l}$ of Dulbecco's modified Eagle's medium with $10 \%$ serum as a chemoattractant. After $24 \mathrm{~h}$ of incubation at $37{ }^{\circ} \mathrm{C}$ under hypoxic and normoxic conditions, noninvading cells and the Matrigel layer were mechanically removed using cotton swabs, and the microporous membrane containing the invaded cells was fixed in 96\% methanol and stained with Diff-Quick staining solutions. Chemotaxis was evaluated by counting the cells that migrated to the lower surfaces of the polycarbonate filters. The numbers of cells in six randomly chosen fields were determined for each filter, and the counts were averaged (means $\pm S D$ ).

\section{In vitro vasculogenic mimicry assay}

The experiments were performed using growth factor-reduced Matrigel at a concentration of $1 \mathrm{mg} / \mathrm{ml}$. Sixty microliters of Matrigel was added to each well of a 96-well plate, allowed to gel for $15 \mathrm{~min}$ at room temperature, and then placed in a humidified atmosphere at $37^{\circ} \mathrm{C}$. Cells $\left(2 \times 10^{4}\right.$ cells per well $)$ were added to the Matrigel-coated plates in a final volume of $200 \mu$ l. The cells were then incubated under hypoxic or normoxic conditions. Thirty-six hours later, images of each well were taken using phase-contrast microscopy.

\section{Assay of intracellular ROS}

Intracellular production of $\mathrm{H}_{2} \mathrm{O}_{2}$ was assayed as previously described [26]. Five minutes before the end of the incubation time, the cells were treated with $5 \mu \mathrm{g} / \mathrm{ml}$ DCF-DA. After being washed with PBS, the cells were lysed in $1 \mathrm{ml}$ of RIPA buffer and analyzed immediately by fluorimetric analysis at $510 \mathrm{~nm}$. Data were normalized to total protein content. Alternatively ROS were measured using Amplex red (Invitrogen), according to the manufacturer's protocol. Cells were lysed in $100 \mu \mathrm{M}$ Amplex red reagent supplemented with $0.2 \mathrm{U} / \mathrm{ml}$ horseradish peroxidase and incubated in the dark for $30 \mathrm{~min}$. Fluorescence was measured in 96-well plates at $590 \mathrm{~nm}$.

\section{Western blot analysis}

Hs29-4T $\left(1 \times 10^{6}\right)$ cells derived from our experimental conditions were lysed for $20 \mathrm{~min}$ on ice in $500 \mu \mathrm{l}$ of complete RIPA lysis buffer (50 mM Tris-HCl, pH 7.5, 150 mM NaCl, 1\% Nonidet P-40, 2 mM EGTA, $1 \mathrm{mM}$ sodium orthovanadate, $1 \mathrm{mM}$ phenylmethanesulfonyl fluoride, $10 \mu \mathrm{g} / \mathrm{ml}$ aprotinin, $10 \mu \mathrm{g} / \mathrm{ml}$ leupeptin). Lysates were separated by SDS/ PAGE and transferred onto nitrocellulose. Immunoblots were incubated in $3 \%$ bovine serum albumin, $10 \mathrm{mM}$ Tris- $\mathrm{HCl}$ ( $\mathrm{pH}$ 7.5), 1 mM EDTA, and 
$0.1 \%$ Tween 20 , for $1 \mathrm{~h}$ at room temperature and probed first with specific antibodies and then with secondary antibodies.

\section{Cell adhesion and spreading}

Cells $\left(10^{6}\right)$ were serum starved for $24 \mathrm{~h}$ before being detached with $0.25 \%$ trypsin for $1 \mathrm{~min}$. Trypsin was blocked with $0.2 \mathrm{mg} / \mathrm{ml}$ soybean trypsin inhibitor, and the cells were resuspended in $2 \mathrm{ml}$ of fresh medium per $10-\mathrm{cm}$ dish, maintained in suspension for $30 \mathrm{~min}$ at $37^{\circ} \mathrm{C}$, and then directly seeded onto culture dishes for various times. Images of each point were taken using phase-contrast microscopy.

\section{Generation of TetO-shRNA inducible vector for Met silencing}

By PCR technology we engineered the pSuper plasmid, substituting the last portion of the $\mathrm{H} 1$ promoter with the TetO sequence to obtain the pSuper TetO vector [27]. We then inserted into pSuper TetO (BglII, HindIII) the already published MET (5'-GUCAUAGGAAGAGGGCAU-3') and Control (5'-CUCAUAGGAAGACCCCAUU-3') targeting sequences [11] and the MET221 (5'-GTGCAGTATCCTCTGACAG-3') targeting sequence [28] to obtain the pSuper TetO-shRNA. We moved (EcoRI, HindIII) the entire construct into the BbsI site of the lentiviral vector pCCLsin.PPT.hPGK.GFP.Wpre [29]. For the TetR vector, the TetR sequence was obtained from pCDNA6/TR and cloned (MscI, NheI) into the lentiviral vector p156RRLsin.PPThCMV.MCS.pre under the control of the cytomegalovirus promoter. See Supplementary Fig. 1 for immunoblot analysis.

\section{Lung colonization assays}

Experiments were conducted in accordance with national guidelines and were approved by the ethics committee of the Animal Welfare Office of the Italian Work Ministry and conformed to the legal mandates and Italian guidelines for the care and maintenance of laboratory animals. Six- to eight-week-old female SCID-bg/bg mice (Charles River Laboratories International, Wilmington, MA, USA) were injected with Hs29-4T cells. Mice (five animals per group) were injected with $2 \times 10^{6} \mathrm{Hs} 29$-4T cells resuspended in $0.2 \mathrm{ml}$ of PBS in the lateral tail vein. The mice were monitored every 3 days and sacrificed after 40 days. Lungs were inspected for metastatic nodules and also weighed to evaluate the total mass of metastases. Organs were fixed overnight at $4{ }^{\circ} \mathrm{C}$ in formalin (5\% in PBS) for histological analyses.

\section{Statistical analysis}

Data are presented as means $\pm S D$ from at least three independent experiments. Statistical analysis of the data was performed using the Student $t$ test. $P$ values of $\leq 0.001$ were considered statistically significant.

\section{Results}

Hypoxia induces a more aggressive phenotype in Hs29-4T melanoma cells

A preliminary screening of growth factor receptors (GF-Rs) regulated by hypoxia on Hs29-4T melanoma cells, including HGF-R/ Met, VEGF-R1, VEGF-R2, EphA2, EphA3, EphB2, platelet derived growth factor $\beta$ receptor (PDGF-R), and fibroblast growth factor-2 receptor, indicated that $1 \% \mathrm{O}_{2}$ mainly leads to increased expression of Met, showing only a marginal effect on VEGF-R2 and being ineffective at the regulation of the other GF-Rs (Supplementary Fig. 1). Hs29-4T melanoma cells were exposed for $24 \mathrm{~h}$ to $1 \% \mathrm{O}_{2}$ hypoxia, leading to the expression of HIF- $1 \alpha$, the known regulator of the transcriptional hypoxic response, as well as increasing the expression of the protooncogene Met. In addition, there was a strong increase in tyrosine phosphorylation of Met due to hypoxia, probably allowing the activation of the kinase and of a scattering/motile behavior (Fig. 1A). Melanoma cells exposed to hypoxia were then analyzed for their adhesion onto fibronectin-coated surfaces. The results indicate that $1 \% \mathrm{O}_{2}$ hypoxia causes a severe increase in the rate of spreading of these cells (Fig. 1B). Hypoxia is highly effective in increasing the ability of melanoma cells to move in a 3D motility assay (Fig. 1C, left), thereby confirming a shift toward a more motile phenotype. In addition to motility we analyzed the effect of hypoxia on the cell ability to cross 3D barriers. The results revealed that hypoxia elicits a proinvasive program in melanoma cells, leading to increased invasiveness (Fig. 1C, right).

The ability to mimic the vasculature, originally observed in melanoma cells and now extended to other cancer models, has been described as a key feature of melanoma malignancy [30,31]. Exposure to hypoxia was able to strongly increase the vasculogenic mimicry of melanoma cells, assayed as their ability to self-organize into vascular-like networks onto Matrigel surfaces (Fig. 1D). Together, these data validate hypoxia as a microenvironmental cue successful in eliciting a wide proinvasive and pseudoangiogenic program in Hs29-4T melanoma cells.

Exposure of Hs29-4T melanoma cells to hypoxia leads to ROS generation and HIF-1 $\alpha$ stabilization

Mild hypoxic conditions $\left(1-3 \% \mathrm{O}_{2}\right)$ have been correlated with oxidative stress, mainly driven by a deregulated mitochondrial electron transport chain [18]. Studies have shown that these mitochondrionderived ROS stabilize and activate HIF- $1 \alpha$, most probably via modulation of PHD activity [18]. To evaluate if Hs29-4T melanoma cells sense hypoxia through a redox-based mechanism, we first evaluated ROS levels in these cells under normoxic and hypoxic conditions, using either DCF-DA or Amplex red redox-sensitive probes. Figs. $2 \mathrm{~A}$ and $\mathrm{B}$ reveal that culture of cells for $24 \mathrm{~h}$ in the presence of $1 \% \mathrm{O}_{2}$ causes a 10-fold increase in intracellular ROS content. Exposure to $1 \% \mathrm{O}_{2}$ is the most effective in terms of ROS delivery (Supplementary Fig. 2). Treatment with selective inhibitors of intracellular ROS sources indicates mitochondria as the main origin, with a marginal contribution by NADPH oxidase. In keeping with the literature [18], the silencing of the Rieske Fe-S protein is dramatically efficient at eliminating mitochondrial ROS, thereby confirming the involvement of mitochondrial complex III in ROS generation during hypoxia. To analyze the role of these ROS in the stabilization of HIF- $1 \alpha$ and in the activation of its target Met we eliminated total mitochondrial ROS by silencing the Rieske Fe-S protein, a component of the mitochondrial transport electron chain acknowledged to produce ROS in response to hypoxia [18], or by treating cells with rotenone (inhibitor of mitochondrial complex I) or with a general scavenger of oxidants such as NAC. Figs. 2C and D indicate that Hs29-4T melanoma cells respond to hypoxia with a redox-dependent HIF- $1 \alpha$ stabilization and increased Met expression, complex III-derived ROS being the main effectors.

Finally we analyzed the role of hypoxia-driven ROS on the motility response induced by $1 \% \mathrm{O}_{2}$. Our data indicate that the increased spreading onto the ECM surface induced by hypoxia is largely dependent on mitochondrial ROS (Fig. 3A), as well as the 3D motility response (Fig. 3B). In addition, the increased ability to cross the 3D Matrigel, an index of the invasiveness of melanoma cells, is again dependent on hypoxia-driven ROS (Fig. 3C), as well as the skill to mimic the vasculature by forming vascular-like networks onto Matrigel surfaces (Fig. 3D).

We can conclude that mitochondrial ROS are key modulators of the hypoxic response, acting on HIF- $1 \alpha$ stabilization and on the proinvasive and vasculogenic mimicry programs initiated by a hypoxic microenvironment.

The hypoxic response of Hs29-4T melanoma cells is mainly HIF-1 $\alpha$ dependent

To confirm the involvement of HIF-1 as the major executor of the hypoxic response in the Hs29-4T melanoma model, we silenced HIF- $1 \alpha$ 
A

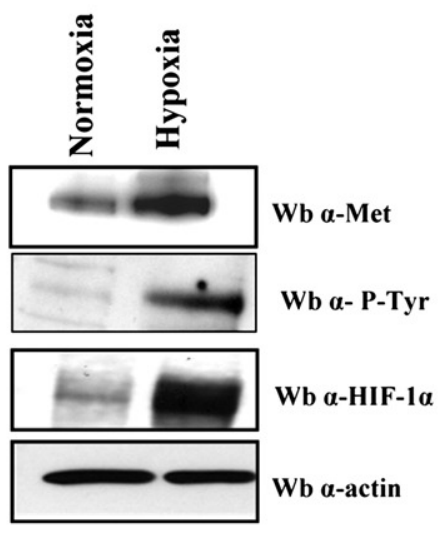

B

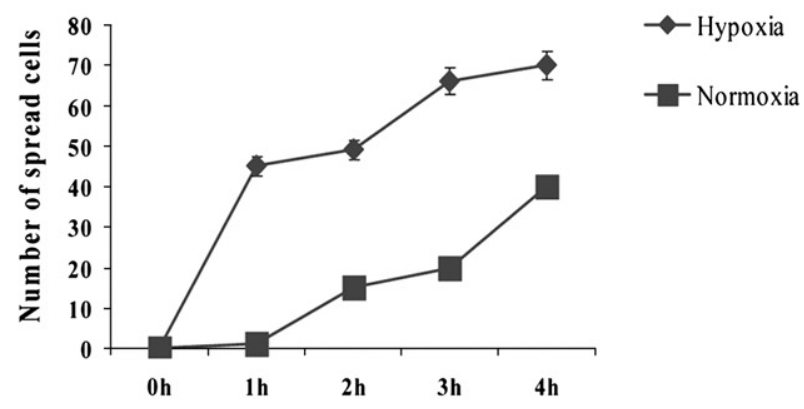

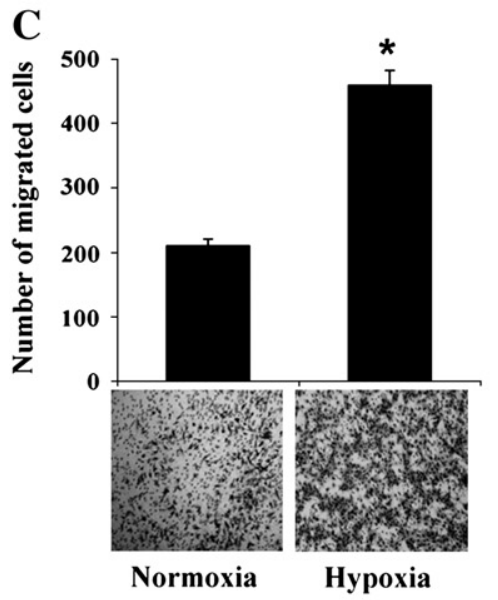

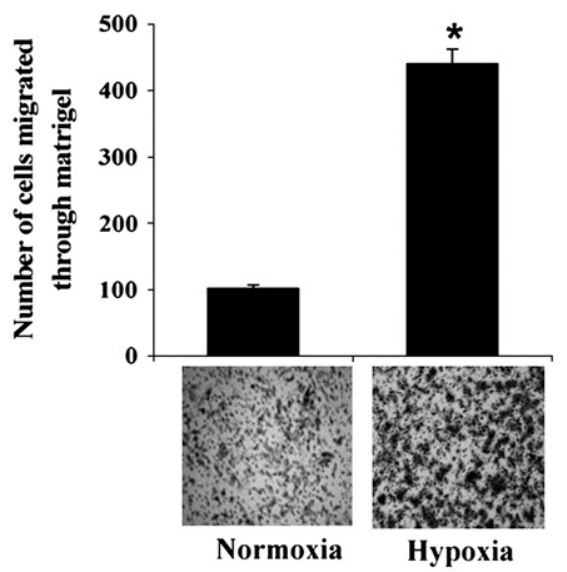

D

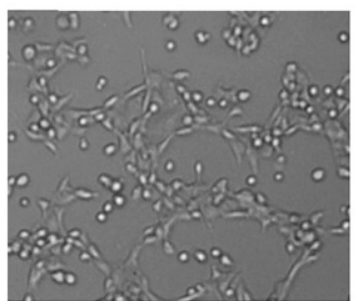

Normoxia
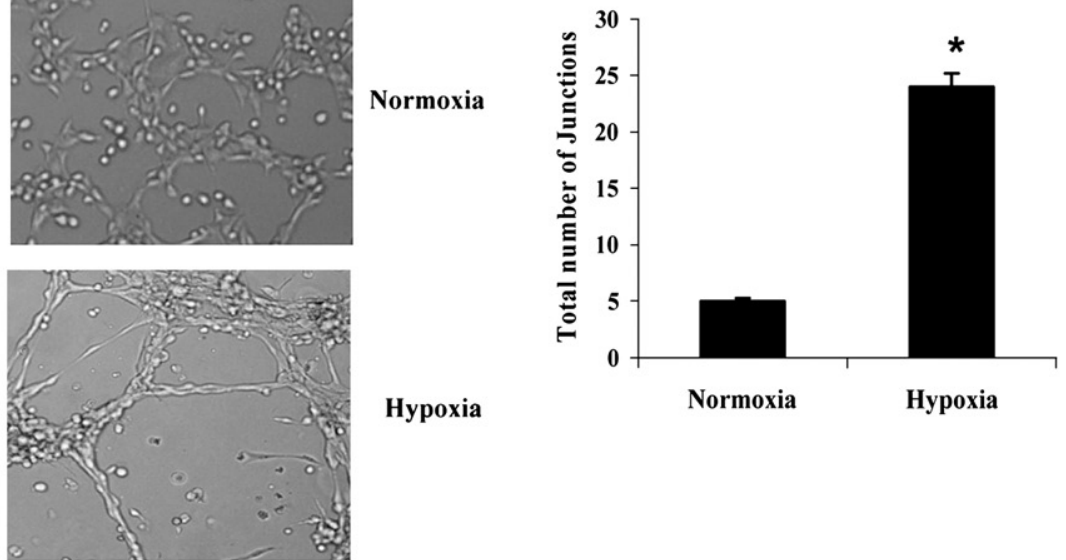

Fig. 1. Hypoxia induces several phenotypic effects in Hs29-4T melanoma cells. (A) Hs29-4T cells were serum starved for $24 \mathrm{~h}$ and then incubated under hypoxia for $24 \mathrm{~h}$. The cells were lysed and immunoblots for HIF-1 $\alpha$, Met, phosphotyrosine (P-Tyr), and actin were performed. (B) Spreading assay. $24 \mathrm{~h}$ after starvation, cells were detached and presuspended for $20 \mathrm{~min}$ in serum-free medium. The cells were exposed to hypoxia and adhesion onto culture dishes was allowed for the indicated times. Spread cells were counted in 10 randomly chosen fields for each sample and the means and SD are shown in the graph. (C) Left: Boyden migration assay. Cells after $24 \mathrm{~h}$ of starvation were allowed to migrate for $24 \mathrm{~h}$ under hypoxia toward medium with $10 \%$ serum as chemoattractant. For each filter the number of cells in 10 randomly chosen fields was determined, and the averages \pm SD were then calculated. ${ }^{*} P<0.001$ versus normoxia. Right: invasiveness assay. Invasiveness was evaluated as for the migration assay (left) except that Matrigel was used to represent 3D ECM. ${ }^{*} P<0.001$ versus normoxia. (D) Analysis of vascular mimicry. Melanoma cells were seeded on Matrigel-coated dishes in serum-free medium and incubated under hypoxia for $36 \mathrm{~h}$. Cord formation was examined with a phase-contrast microscope and the bar graph quantifies the total number of junctions. ${ }^{*} P<0.001$ versus normoxia. All data are representative of at least three independent experiments.

by RNA interference (Supplementary Fig. 3) and again assayed cell spreading, 3D motility, and invasiveness, as well as vasculogenic mimicry of hypoxic cells (Fig. 4). The forced down-regulation of the HIF- $1 \alpha$ protein completely abolished the adhesive, motile, and proinvasive effect induced by hypoxia (Figs. 4A-C). In addition, inhibition of expression of HIF-1 $\alpha$ was able to severely impair the ability of melanoma cells to self-organize in vascular-like structures onto Matrigel-coated dishes (Fig. 4D). On this basis, HIF-1 is probably the critical modulator of the motility program of aggressive melanoma in a hypoxic environment. 
The motility program engaged by hypoxia in aggressive melanoma relies on Met activation

The proto-oncogene Met is acknowledged to promote motility and scattering of cancer cells from their primary site, thus playing an important role in the early stages of metastasis [11,32]. In addition

A

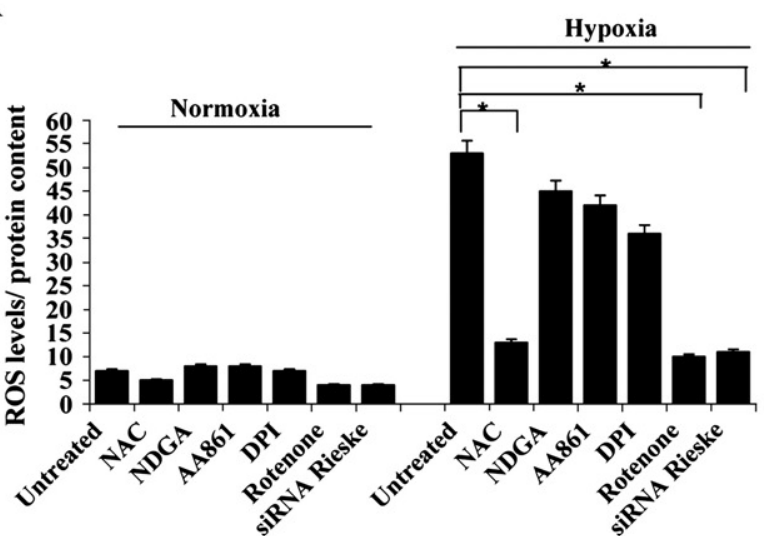

B

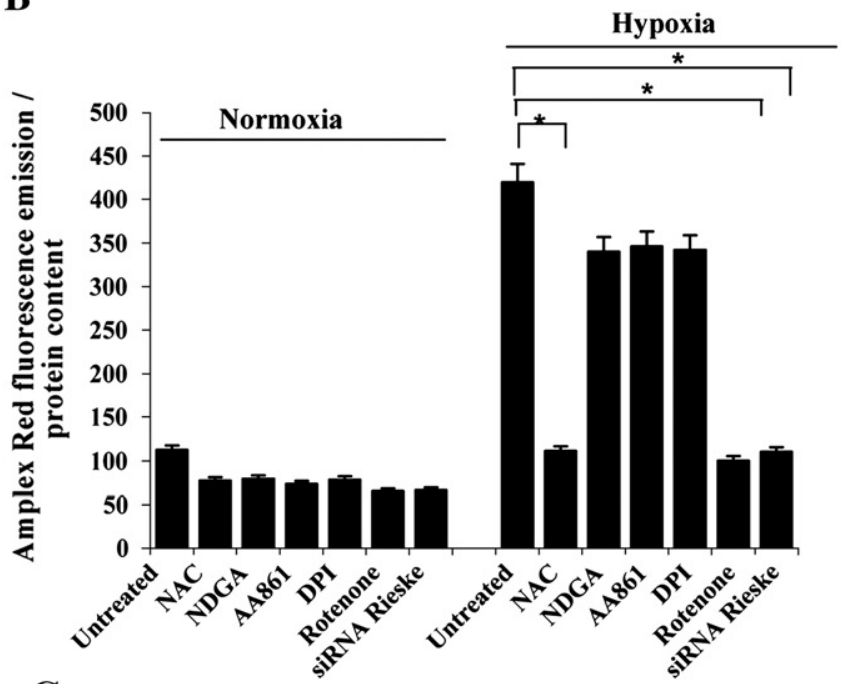

C

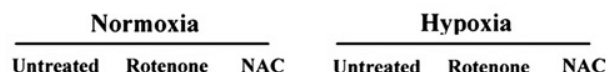

Wb $\alpha$-HIF-10

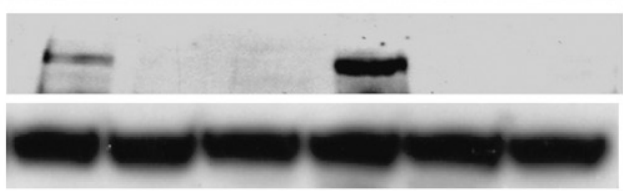

Wb $\alpha$-Met

Wb $\alpha$-actin

D

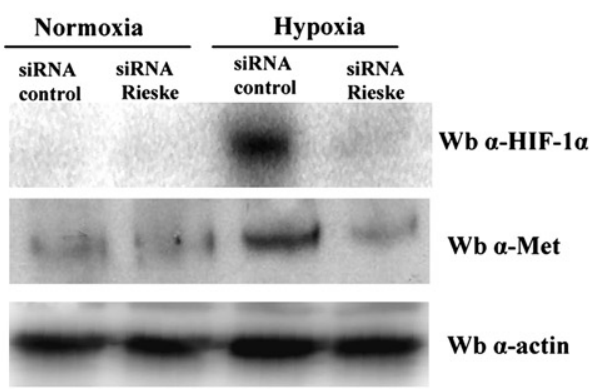

tumor-associated hypoxia enhances transcription of the Met gene and amplifies the invasive response of tumor cells to the ligand hepatocyte growth factor [11]. These preliminary observations have provided the rationale for investigating the significance of hypoxia-induced Met activation during exposure of Hs29-4T melanoma to $1 \% \mathrm{O}_{2}$. We first confirmed that in Hs29-4T the hypoxia-driven Met overexpression is HIF-1 $\alpha$-dependent (Fig. 5A). We therefore silenced the Met protooncogene in Hs29-4T cells using an inducible lentiviral delivery system of RNA interference. This system has already been accredited in tumor cells overexpressing Met, in which Met silencing impaired tumor growth and metastasis formation and maintenance [33]. As a second approach we used the Met-selective tyrosine kinase inhibitor PHA-665752, acknowledged to reverse lung premalignancy induced by mutant K-Ras and to inhibit in vivo Met-dependent tumorigenicity in various murine tumor models [34]. We thus assayed under normoxic and hypoxic conditions the spreading/motility response (Figs. 5B and C), as well as melanoma plasticity in terms of its ability to form vascular-like structures upon Met silencing or inhibition (Fig. 5D). Our observations support the notion that the activation of the motile and proinvasive program of aggressive melanoma cells exposed to hypoxia is strictly dependent on overexpression and activation of Met. Indeed, Met silencing led to a dramatic decrease in migration and invasion induced by hypoxia, as well as in the vasculogenic mimicry (Figs. 5C and D). The effect of Met silencing was less pronounced for spreading onto fibronectin (Fig. 5B). Furthermore, the ability of the tyrosine kinase inhibitor PHA to fully mimic the effect of Met silencing is in keeping with the idea that hypoxia-driven Met overexpression leads to its activation.

Hypoxia drives dissemination of aggressive melanoma cells through a redox-dependent pathway involving HIF-1 $\alpha$ and Met

To investigate if the redox-dependent HIF- $1 \alpha /$ Met synergy is required for metastasis onset, we chose a lung colony formation assay in SCID mice. This assay assesses the ability of tumor cells to survive in the bloodstream, to extravasate, and to reside in a new location, originating metastatic tumors. The tail-injection experimental metastasis assay does not fully recapitulate the naturally occurring metastatic process from the beginning, but it is widely considered a valuable experimental tool to assess the intermediate and terminal phases of the metastatic program. Indeed, our experimental design is based on in vitro mimicry of hypoxic/oxidative environmental conditions and in vivo analysis of lung colonization of conditioned melanoma cells. To analyze the roles of both ROS delivery and Met expression in hypoxia we silenced the Rieske protein and Met kinase. Maintenance of Rieske protein and Met silencing was checked in vitro for up to 9 days, a realistic time to influence homing and survival of melanoma cells in lung parenchyma (Supplementary Fig. 4). After $24 \mathrm{~h}$ of hypoxic preconditioning we injected $1 \times 10^{6} \mathrm{Hs} 29-4 \mathrm{~T}$ cells silenced for Rieske protein or Met kinase into mouse tail veins. After 4 weeks mice of each experimental group were sacrificed to evaluate

Fig. 2. Hypoxia leads to an increase in intracellular ROS. (A) Hs29-4T cells were serum starved for $24 \mathrm{~h}$ and treated under hypoxia with specific inhibitors of the various ROS sources ( $20 \mathrm{mM}$ NAC, $5 \mu \mathrm{M}$ NDGA, $10 \mu \mathrm{M}$ DPI, $1 \mu \mathrm{M}$ rotenone) or transfected with siRNA for Rieske Fe-S protein. Hydrogen peroxide production was evaluated with DCFDA and normalized to total protein content. ${ }^{*} P<0.001$ versus untreated under hypoxia. (B) Cells were treated as in (A) and hydrogen peroxide production was evaluated with Amplex red reagent. ${ }^{*} P<0.001$ versus untreated under hypoxia. (C) Melanoma cells, after $24 \mathrm{~h}$ of starvation, were incubated under hypoxia for $24 \mathrm{~h}$ in the presence of $20 \mathrm{mM} \mathrm{NAC}$ and $1 \mu \mathrm{M}$ rotenone. Lysates were used for Western blot analysis for HIF-1 $\alpha$ and actin for normalization. (D) Cells were previously transfected with siRNA targeting the Rieske Fe-S protein and, after $24 \mathrm{~h}$ of serum starvation, were exposed to $24 \mathrm{~h}$ of hypoxia. Lysates were used for Western blot analysis for HIF- $1 \alpha$ and Met, as well for actin for normalization. All the results are representative of four independent experiments. 
A

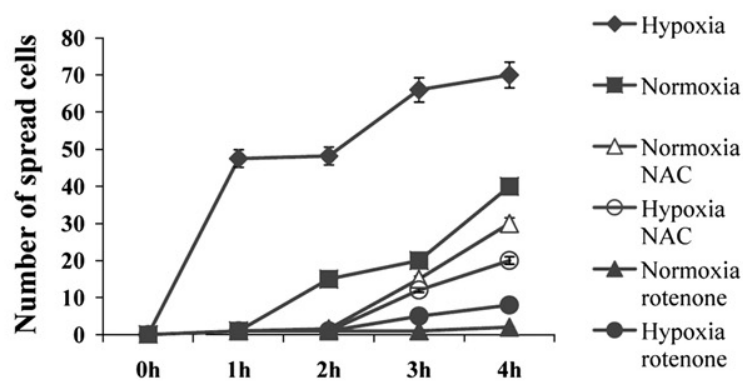

B

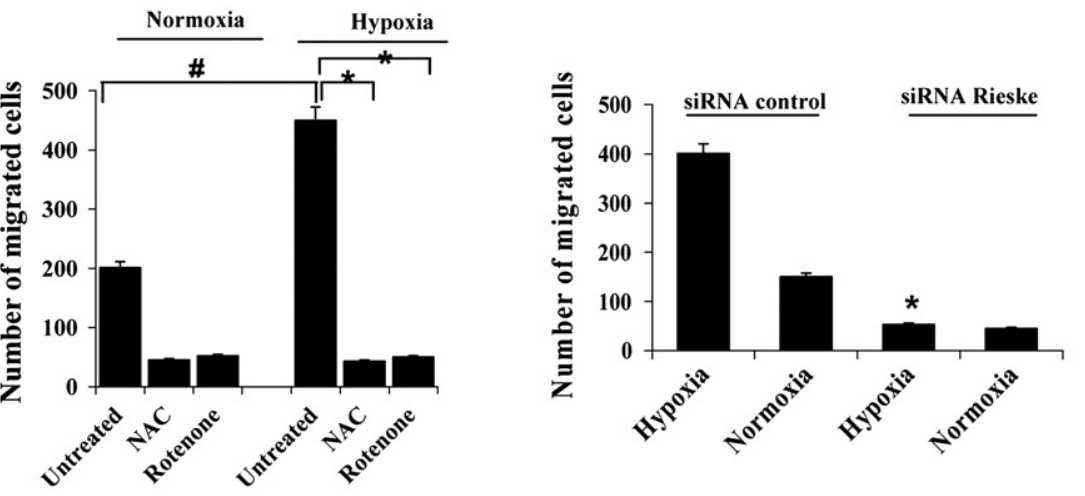

C
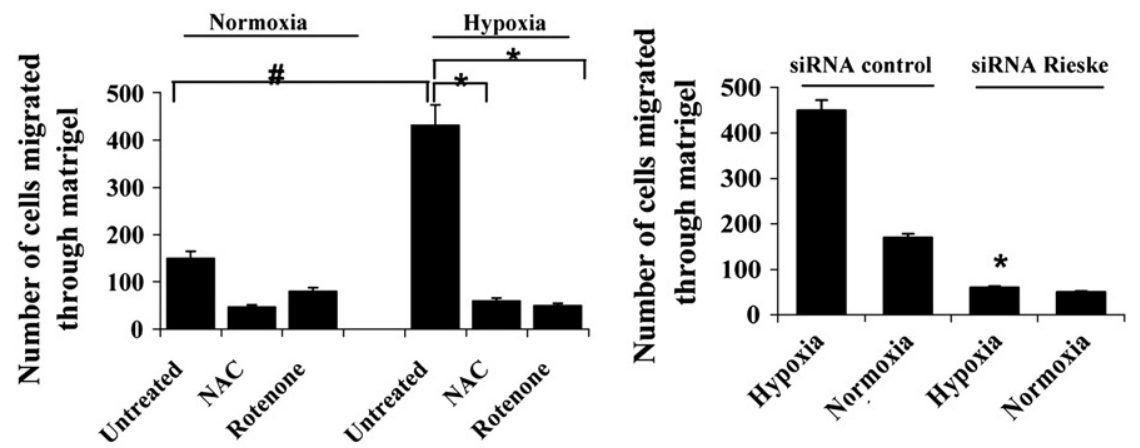

D
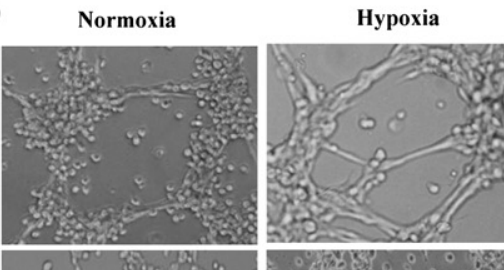

Control
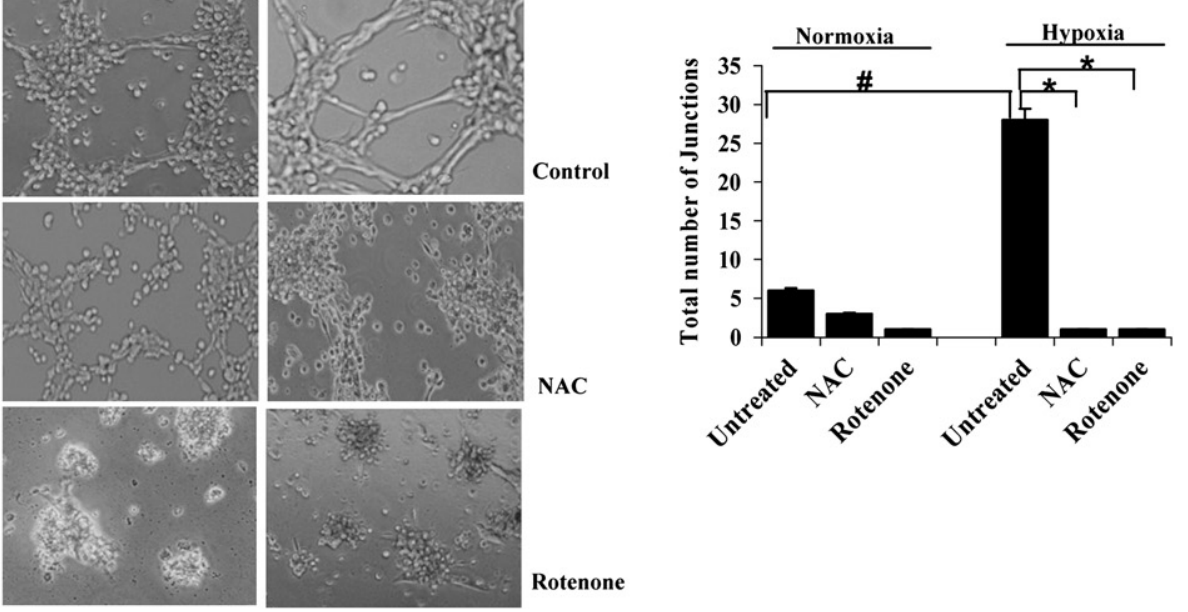

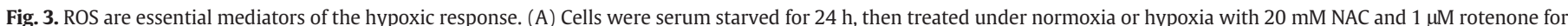

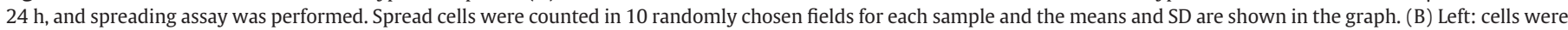

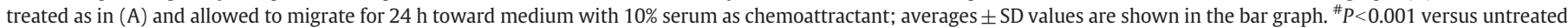

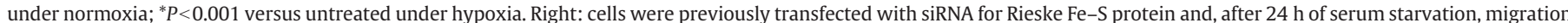

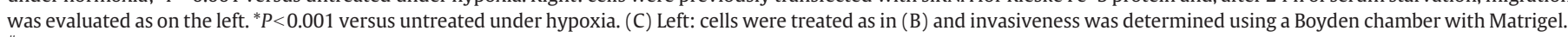

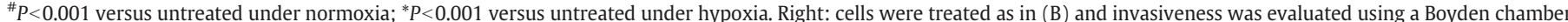

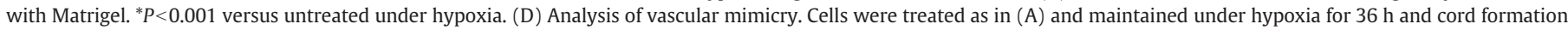

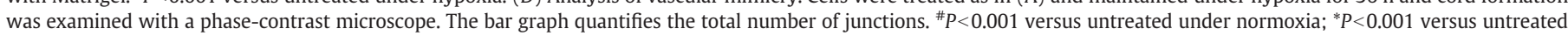
under hypoxia. All data are representative of at least three independent experiments. 
A

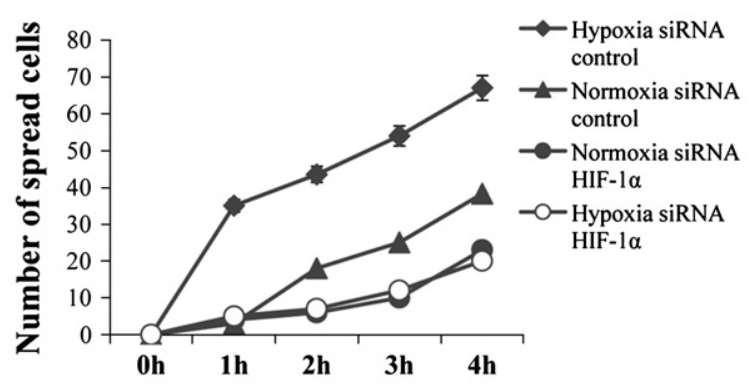

B

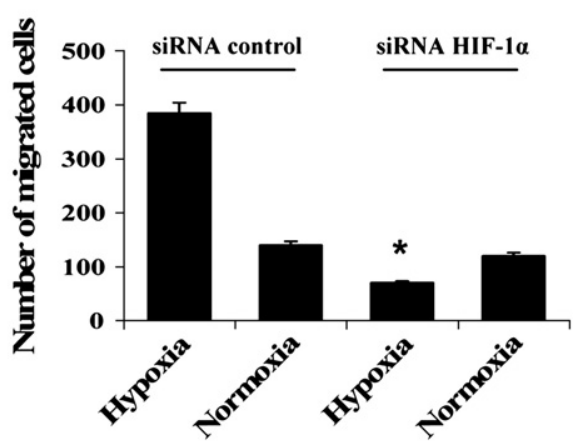

C

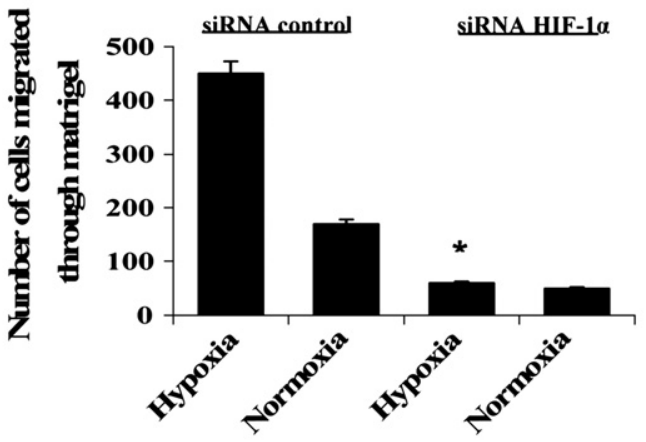

D
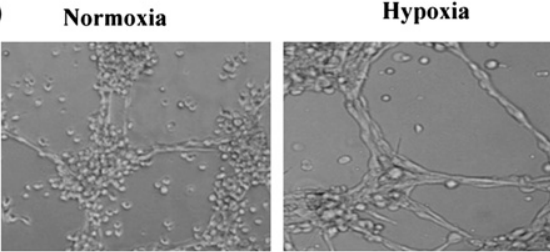

siRNA
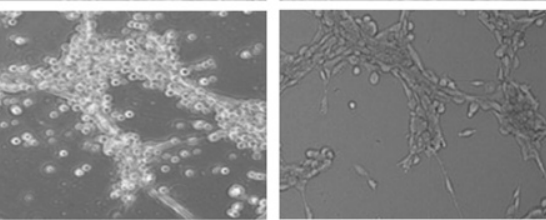

control

SiRNA HIF-1a

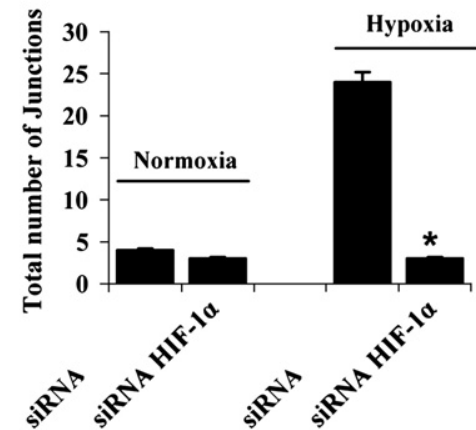

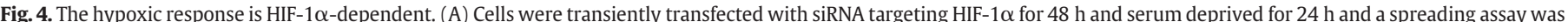

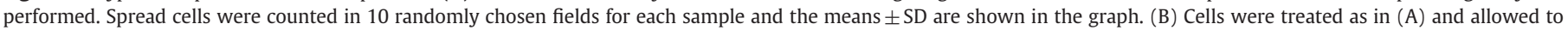

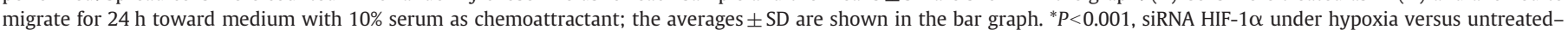

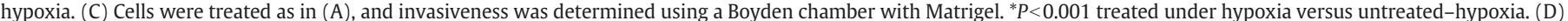

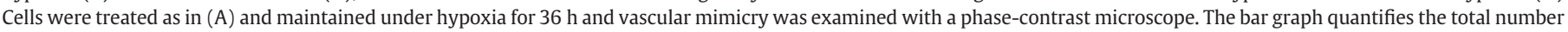
of junctions. ${ }^{*} P<0.001$ versus untreated-hypoxia. All data are representative of at least three independent experiments.

formation of lung colonies. We observed that hypoxia gave rise to a strong increase in the number of melanoma colonies, suggesting that the hypoxic preconditioning of melanoma cells is sufficient to give them a prometastatic spur (Fig. 6A). The number of lung colonies is greatly decreased in cells with the Rieske protein or Met kinase silenced, confirming the roles of both mitochondrial ROS generation and Met expression in metastatic lung colonization of melanoma cells (Fig. 6A). In a further experiment, the preconditioning of hypoxic Hs29-4T melanoma cells with NAC to scavenge intracellular ROS, with rotenone to eliminate mitochondrial ROS, or with PHA to inhibit Met tyrosine kinase activity confirmed our observations on metastatic growth (Fig. 6B). Indeed, after $24 \mathrm{~h}$ of hypoxic preconditioning (and 1 h pretreatment with NAC/rotenone/PHA) we injected $2 \times 10^{6} \mathrm{Hs} 29$ 4T cells into tail veins, and 6 weeks later the animals were sacrificed and lungs inspected. Because of the large and confluent superficial lung metastases, lungs were weighed and total tumor load is reported in Fig. 6B. Lung slices were stained with hematoxylin and eosin (H\&E) (Fig. 6C) [31]. The specificity of the hypoxic response was confirmed by the ability of HIF- $1 \alpha$ siRNA to block the increase in lung colonization. Upon Met inhibition, as well as ROS removal by NAC or inhibition of mitochondrial release of ROS by rotenone, animals showed a reduced total lung metastatic load (Figs. 6B and C).

In the last experiment we also examined the morphology of large metastases to analyze melanoma vasculogenic mimicry, i.e., the unique ability of aggressive melanoma cells to form tubular structures and patterned networks in three-dimensional culture that mimic embryonic vasculogenic structures [31]. Indeed, histological analysis of melanoma or in vivo use of intravenous tracers has revealed the architecture of aggressive melanoma to consist of nonvascular laminin-rich networks surrounding tumor cells and containing red blood cells, possibly serving 
A

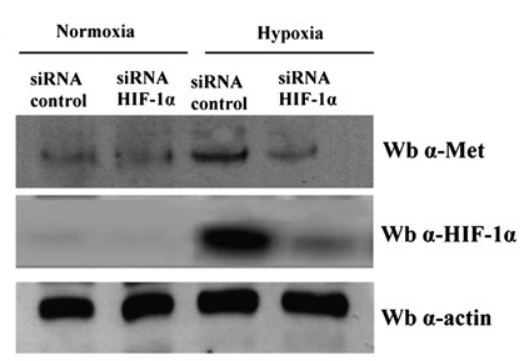

B

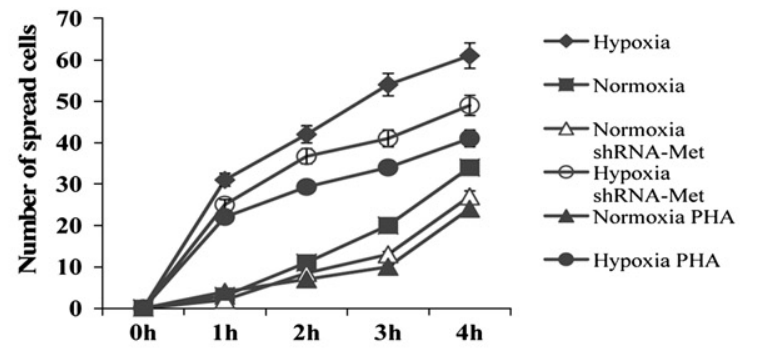

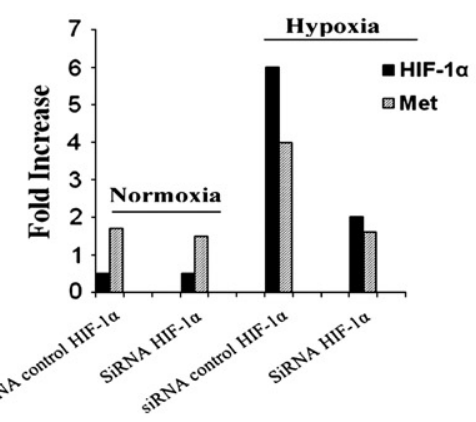

HIF-1a

Met

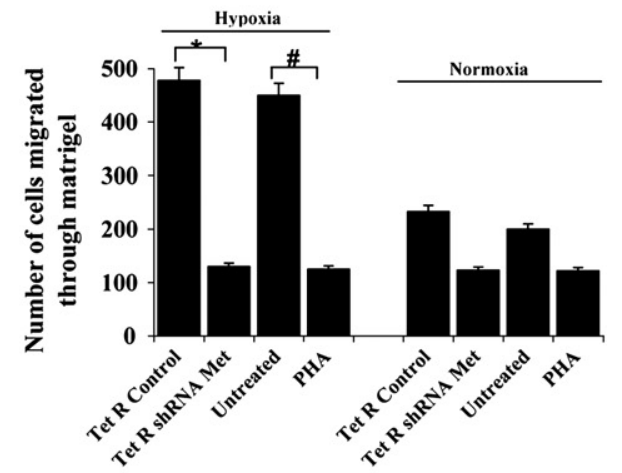

D

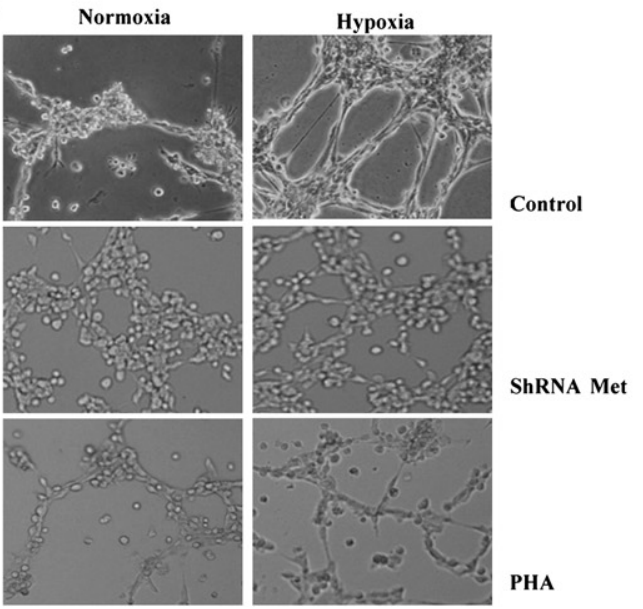

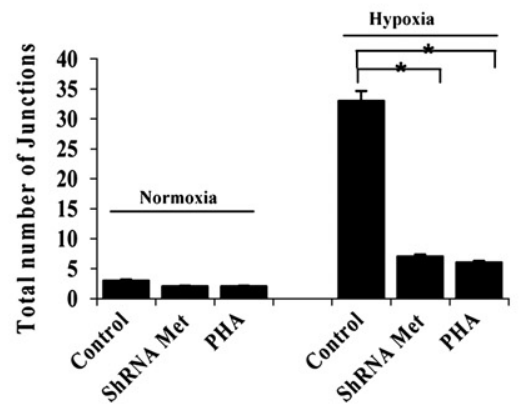

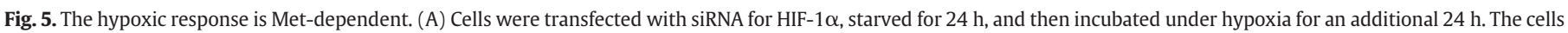

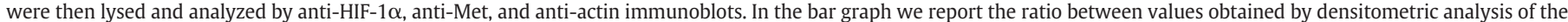

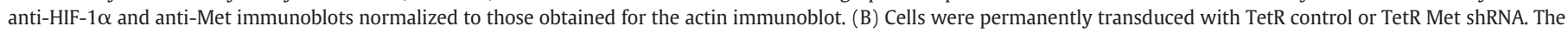

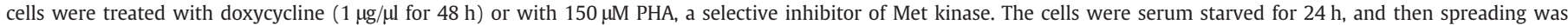

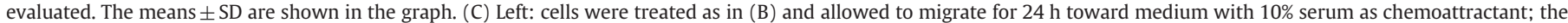

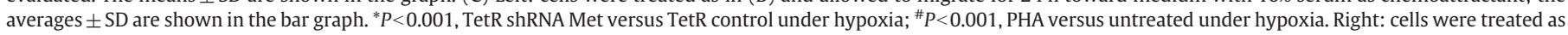

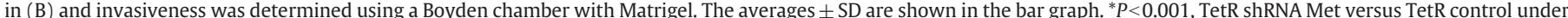

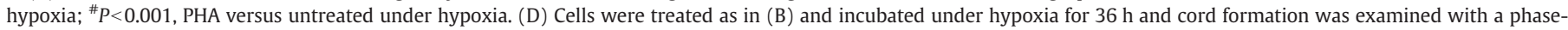

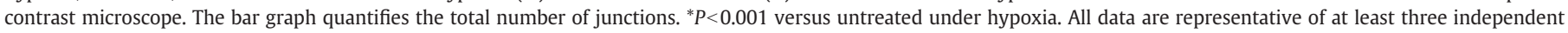
experiments.

as additional perfusion mechanisms and allowing dissemination [35]. Of note, tumors exhibiting vasculogenic mimicry have a poor prognosis [36]. The analysis of laminin/H\&E-stained lung metastases reveals that activation of the ROS/HIF-1/Met axis is mandatory for in vivo vasculogenic mimicry. Indeed, metastases obtained from hypoxic cells show a high level of laminin staining, as well as several non-endothelial cell-lined 
channels filled with red blood cells (Fig. 6D). Both laminin staining and formation of vascular-like channels are totally absent from tumors from normoxic cells, or from hypoxic cells silenced for HIF- $1 \alpha$, or treated with inhibitors of mitochondrial ROS delivery or Met kinase (Fig. 6D), thereby confirming the biological significance of this molecular pathway for vasculogenic mimicry of aggressive melanoma.

Taken together these data indicate that in Hs29-4T melanoma cells oxidative stress after hypoxia leads to persistent expression of HIF-1 $\alpha$ and its target Met, a mandatory prerequisite sufficiently recapitulating the early phases of cancer progression toward metastatic colonization of lungs.

\section{Discussion}

The results presented in this report lead to these major conclusions: (1) in Hs29-4T human melanoma cells hypoxia leads to a redoxdependent stabilization of HIF- $1 \alpha$, mainly mediated by mitochondrial ROS, and (2) HIF- $1 \alpha$ accumulation, in turn, leads to enhanced expression and activation of the proto-oncogene Met and to activation of: (i) the motogenic program, (ii) invasiveness and ability to disseminate metastatic colonies of melanoma cells, and (iii) the skill to mimic the vasculature, forming capillary-like structures and expressing a latent "pseudoangiogenic" program. Hence, activation of Met-driven motogenic/invasive pathways by HIF, in which ROS are mandatory players, may represent an escape, oxygen-seeking strategy to avoid the hypoxic hostile environment.

Although the involvement of ROS as procarcinogenic agents has been strongly supported by the past literature [37-39], their role in the acquisition of an invasive and malignant phenotype is still not fully understood. It is well established that NADPH oxidase is responsible for the generation of intracellular ROS triggered by several growth factors such as PDGF, HGF, insulin, and VEGF, as well as integrins, thereby triggering many of the effects elicited by these factors, including cell proliferation, migration, cytoskeletal remodeling, angiogenesis, and regulation of genes associated with tumor metastasis [39,40]. Mild hypoxia, ranging from 1 to $3 \%$, has already been reported to generate a state of oxidative stress. During hypoxia, ROS have been reported to be mainly produced by deregulated mitochondria through complexes I, III, and IV, although complex III is the only mitochondrial complex able to release ROS on the cytoplasmic side of the membrane and to contribute cytoplasmic oxidants [18,41]. In endothelial cells, NADPH oxidase has been indicated as a source of ROS in hypoxia as well [40]. In keeping with these indications, in the Hs29-4T melanoma model, hypoxia-driven ROS are mainly produced by the mitochondrial electron transfer chain, as indicated by the ability of rotenone to counteract ROS generation; complex III is likely to be the main source, as revealed by the effect of silencing of Rieske Fe-S protein, a component of the complex III ubiquinol $\mathrm{Q}$ cycle. Although we cannot exclude a contribution of NADPH oxidase to hypoxic oxidative stress, the ability of diphenylene iodonium (DPI), a flavin-dependent oxidase inhibitor, to decrease ROS release during hypoxia and to block HIF- $1 \alpha$ accumulation may be explained by its effect on the flavoproteins of the mitochondrial electron transfer chain.

The state of the art strongly implicates ROS in the activation of the epithelial-mesenchymal transition (EMT) in several cancer models, including melanoma. Rac1b, a differentially spliced form of Rac1, has been reported to generate carcinogenic ROS during metalloproteaseinduced EMT of mammary epithelial cells [42]. In keeping with this, Rac1-mediated redox signaling has been reported as vital for melanoma aggressiveness upon expression and activation of Met, a known regulator of the EMT [32,43]. Hypoxia has already been correlated with EMT and the consequent acquisition of a motile/invasive behavior [44]. In several epithelial cancers, hypoxia-driven generation of ROS revealed a redox regulation of early EMT-related events induced by hypoxia such as activation of the Snail and Twist transcription factors, which are probably engaged in the transcription of HIF- $1 \alpha$ and VEGF [44]. Our data confirm a key role for hypoxia-driven ROS in aggressive melanoma, through HIF-1 $\alpha$ accumulation and Met-induced expression, leading to the achievement of a motile and invasive behavior. Indeed, elimination of mitochondrial ROS release, counteracting HIF- $1 \alpha$ accumulation, and inhibition of Met activity or expression are all able to strongly decrease the aggressiveness of Hs29-4T melanoma cells, both in vitro and in vivo.

In the melanoma model studied, hypoxia-driven ROS are absolutely mandatory to allow accumulation of HIF- $1 \alpha$. Although the involvement of EMT-related events is possible and could in principle lead to an accumulation of HIF- $1 \alpha$ through activation of the Twist transcription factor [45], in hypoxic Hs29-4T cells we did not detect the activation of a clear EMT transcriptional program, as indicated by E-cadherin preservation and the inability to express Twist or Snail transcription factors (data not shown). Hence, we think that HIF-1 $\alpha$ accumulation due to hypoxic ROS may be explained through the redox-mediated inactivation of PHDs, in which ROS enzymatically inactivate PHDs through a Fenton reaction with the catalytic $\mathrm{Fe}^{2+}[18,41,46]$. In keeping with this idea, in other cancer models mitochondrial DNA mutations associated with increased generation of ROS promote normoxic accumulation of the factor [47] and H-Ras stabilizes the hypoxic factor through the generation of superoxide anion [48].

Hypoxia promotes tumor progression essentially by two mechanisms. First, deep hypoxia, because of its toxicity to both normal and tumor cells, selects for cells with mutations that allow survival under these extreme conditions $[49,50]$. Second, hypoxia activates several signaling pathways triggering de novo vascularization and facilitating tumor cell invasion, migration, and adhesion, thereby contributing to tumor malignancy. In addition to activation of proper neoangiogenesis, hypoxia has also been linked with the ability of melanoma cells to organize into perfusable vascular-like networks, a process called vasculogenic mimicry, serving for metastatic dissemination [25]. Our data indicate that ROS, HIF-1 $\alpha$ stabilization, and the consequent Met overexpression and activation are strongly involved in hypoxiamediated vasculogenic mimicry. The effects of intratumoral hypoxia in stimulating vasculogenic mimicry of melanoma may contribute a possible explanation for the astonishing prometastatic effect of angiogenesis inhibitors [5-7], totally inactive on nonendothelial de novo vascularization. Indeed it is possible that cells exposed to hypoxia after VEGF-targeted therapies exploit nonendothelial perfusable networks to escape the primary tumor and disseminate metastases. In this light, activation of the ROS/HIF/Met invasive program by hypoxia leads to overcoming the need for the "angiogenic shift" of tumors.

The Met proto-oncogene, encoding the tyrosine kinase receptor for HGF, senses hostile environmental conditions and drives cell invasion and metastasis, and its overexpression has been correlated with poor prognosis of cancers [32,34]. Overexpression of the proto-oncogene Met has already been reported to be induced by HIF-1, as well as leading to constitutive activation of the receptor [11]. Notably, Met silencing in already established metastases led to their almost complete regression, indicating that persistent expression of Met is mandatory until the advanced phases of cancer progression [33]. ROS have already been involved as downstream effectors of the Met proto-oncogene. Indeed, expression of Met has been correlated with melanoma aggressiveness in B16 mouse cells, and Rac1-mediated redox signaling has been reported to be vital for expression and activation of Met [12]. We herein report that in Hs29-4T melanoma cells hypoxia-driven ROS behave as upstream modulators of Met expression and consequently of the activation of its invasive program. We indeed report that Met expression is dependent on hypoxia-driven ROS, but the analysis of a reciprocal relationship among mitochondrial ROS, HIF- $1 \alpha$, and Met revealed a precise hierarchy: hypoxia leads to mitochondria deregulation and ROS generation, which, in turn, stabilizes the HIF- $1 \alpha$ transcription factor, whose effector arm in the activation of the metastatic program is the Met proto-oncogene. Of note, we correlate for the first time Met expression with the ability of melanoma cells to form vessel-like structures, generally recognized as a 
A

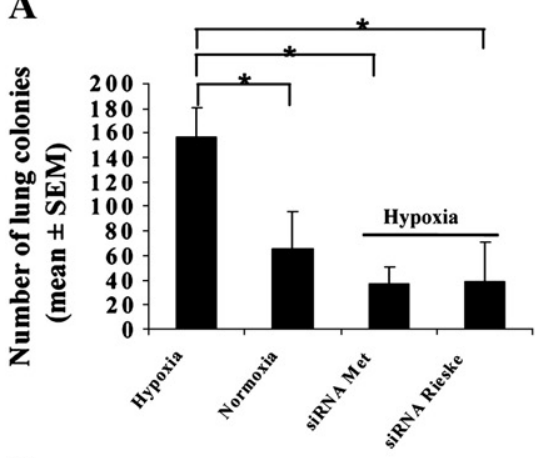

B

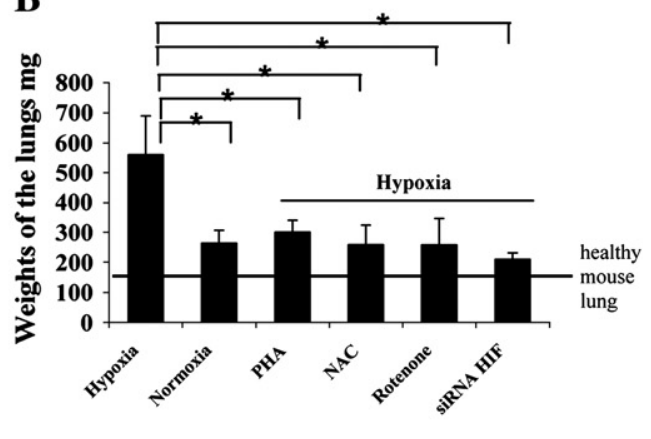

C
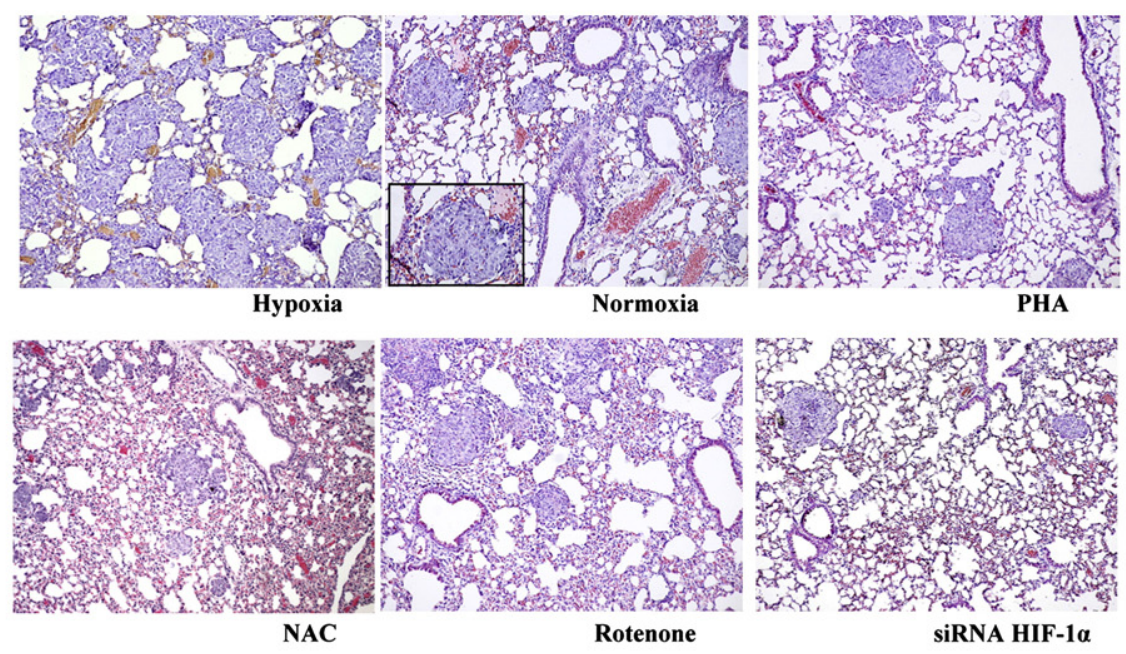

D
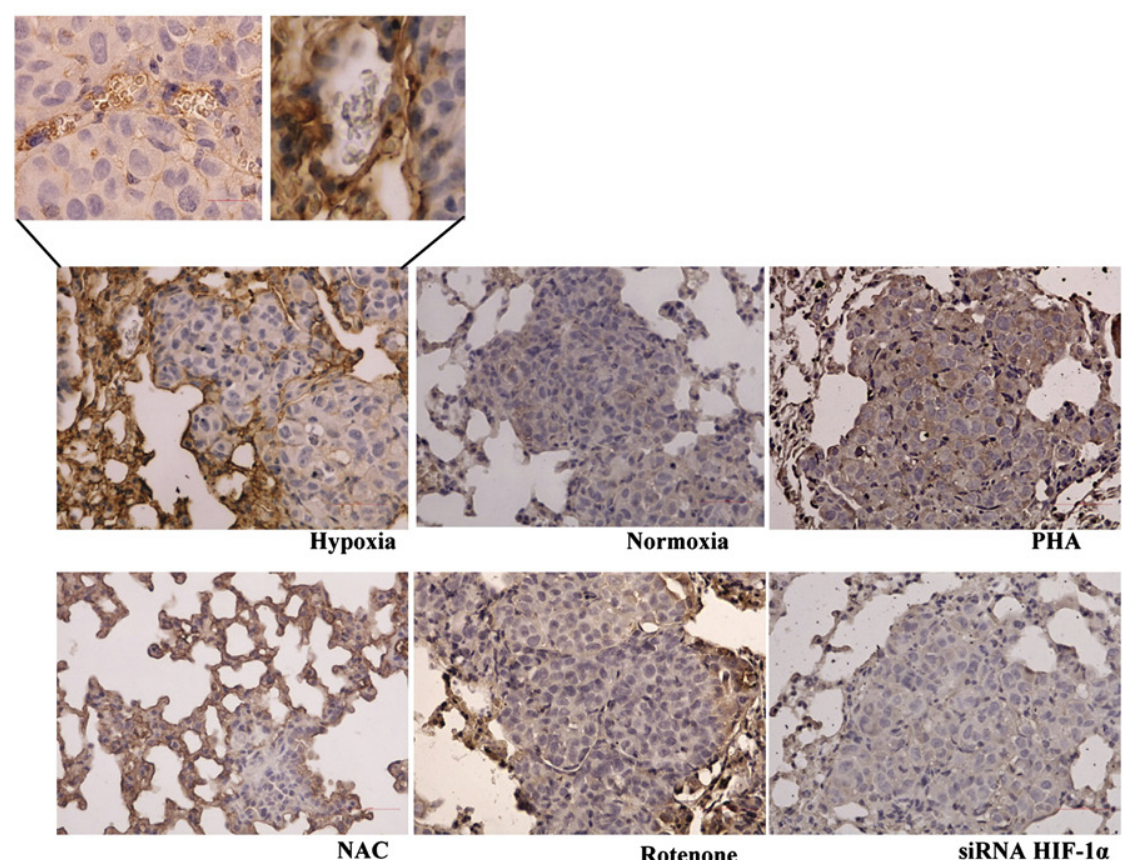

$\begin{array}{lllllll} & \text { Hypoxia } & \text { Normoxia } & \text { PHA } & \text { NAC } & \text { Rotenone } & \text { siHI } \\ \begin{array}{l}\text { Laminin } \\ \text { Expression }\end{array} & +++ & - & +/- & +/- & +/- & - \\ \text { RBCs channels } & + & - & - & - & - & -\end{array}$


new pattern of nonendothelial tumor neovascularization, observed in several tumor types and strongly associated with a poor prognosis.

Activation of HIF- $1 \alpha$ is mandatory for several responses, which, coordinately, instruct aggressive cancer cells to escape from adverse conditions within the primary tumor [51]. First, HIF-1 activates the survival pathway, acting on inhibition of proapoptotic routes such as Bad and Bid and activation of secretion of prosurvival factors such as VEGF, Bcl-2, and myeloid cell leukemia-1 [51,52]. In addition, in hepatoma cells, mitochondrial ROS due to hypoxia lead to activation of the prosurvival pathway driven by nuclear factor- $\kappa \mathrm{B}$, through oxidation/activation of the kinase Src and phosphorylation of the p65 inhibitor of nuclear factor- $\kappa \mathrm{B}[51,53]$. This is a compulsory protection system from an incremental danger, i.e., the decrease in $\mathrm{O}_{2}$. Second, $\mathrm{HIF}$ $1 \alpha$ activates a metabolic shift toward a more reducing catabolism involving glycolysis, producing NADPH through the pentose phosphate pathway and excluding the strongly oxidizing mitochondria. Third, HIF$1 \alpha$ elicits the metastatic escape program from the hostile hypoxic site. Much evidence of the redox regulation of several key points of these three programs is available in the literature and was recently reviewed by Snyder and Chandel [41] and Pani et al. [51]. Here we propose that hypoxia-driven ROS, through stabilization of the master regulator HIF$1 \alpha$ and transcriptional regulation of Met, are central players in the various strategies adopted by cancer cells to escape from unfavorable sites and suggest that hypoxic conditions and ROS can hierarchically cooperate in inducing metastasis outcomes.

The findings reported herein significantly contribute to our understanding of the role of ROS in tumor progression, changing the current perspective that oxidants mainly act by increasing oxidative DNA damage and mutations. Recently, Gao et al. [20] analyzed three different tumorigenic in vivo mouse models and elegantly showed that antioxidants exert their antitumoral effect mainly acting on the HIF- $1 \alpha$ level. Our results extend the key role of HIF- $1 \alpha$ redox stabilization from carcinogenesis to metastatic dissemination of aggressive tumors, suggesting antioxidant therapy as a promising adjuvant treatment for malignant melanoma.

Supplementary materials related to this article can be found online at doi:10.1016/j.freeradbiomed.2011.05.042.

\section{Acknowledgments}

This work was supported by the Associazione Italiana Ricerca sul Cancro, Istituto Toscano Tumori, Region Toscana, and Fondazione Cassa di Risparmio di Lucca.

\section{References}

[1] Vaupel, P.; Mayer, A. Hypoxia in cancer: significance and impact on clinical outcome. Cancer Metastasis Rev. 26:225-239; 2007.

[2] Vaupel, P.; Hockel, M.; Mayer, A. Detection and characterization of tumor hypoxia using $\mathrm{pO}_{2}$ histography. Antioxid. Redox Signal. 9:1221-1235; 2007.

[3] Semenza, G. L. Defining the role of hypoxia-inducible factor 1 in cancer biology and therapeutics. Oncogene 29:625-634; 2009.

[4] Lartigau, E.; Randrianarivelo, H.; Avril, M. F.; Margulis, A.; Spatz, A.; Eschwege, F., et al. Intratumoral oxygen tension in metastatic melanoma. Melanoma Res. 7:400-406; 1997

[5] Ebos, J. M.; Lee, C. R.; Cruz-Munoz, W.; Bjarnason, G. A.; Christensen, J. G.; Kerbel, R. S. Accelerated metastasis after short-term treatment with a potent inhibitor of tumor angiogenesis. Cancer Cell 15:232-239; 2009.

[6] Loges, S.; Mazzone, M.; Hohensinner, P.; Carmeliet, P. Silencing or fueling metastasis with VEGF inhibitors: antiangiogenesis revisited. Cancer Cell 15: 167-170; 2009
7] Paez-Ribes, M.; Allen, E.; Hudock, J.; Takeda, T.; Okuyama, H.; Vinals, F., et al. Antiangiogenic therapy elicits malignant progression of tumors to increased local invasion and distant metastasis. Cancer Cell 15:220-231; 2009.

[8] Nguyen, D. X.; Bos, P. D.; Massague, J. Metastasis: from dissemination to organspecific colonization. Nat. Rev. Cancer 9:274-284; 2009.

[9] Huang, C. H.; Yang, W. H.; Chang, S. Y.; Tai, S. K.; Tzeng, C. H.; Kao, J. Y., et al. Regulation of membrane-type 4 matrix metalloproteinase by SLUG contributes to hypoxia-mediated metastasis. Neoplasia 11:1371-1382; 2009.

[10] Krishnamachary, B.; Berg-Dixon, S.; Kelly, B.; Agani, F.; Feldser, D.; Ferreira, G., et al. Regulation of colon carcinoma cell invasion by hypoxia-inducible factor 1 . Cancer Res. 63:1138-1143; 2003.

[11] Pennacchietti, S.; Michieli, P.; Galluzzo, M.; Mazzone, M.; Giordano, S.; Comoglio, P. M. Hypoxia promotes invasive growth by transcriptional activation of the Met protooncogene. Cancer Cell 3:347-361; 2003.

[12] Hirota, K.; Semenza, G. L. Regulation of angiogenesis by hypoxia-inducible factor 1. Crit. Rev. Oncol. Hematol. 59:15-26; 2006.

[13] Karashima, T.; Sweeney, P.; Kamat, A.; Huang, S.; Kim, S. J.; Bar-Eli, M., et al. Nuclear factor-kappaB mediates angiogenesis and metastasis of human bladder cancer through the regulation of interleukin-8. Clin. Cancer Res. 9:2786-2797; 2003.

[14] Rohwer, N.; Welzel, M.; Daskalow, K.; Pfander, D.; Wiedenmann, B.; Detjen, K., et al. Hypoxia-inducible factor 1alpha mediates anoikis resistance via suppression of alpha5 integrin. Cancer Res. 68:10113-10120; 2008.

[15] Erler, J. T.; Bennewith, K. L.; Cox, T. R.; Lang, G.; Bird, D.; Koong, A., et al. Hypoxiainduced lysyl oxidase is a critical mediator of bone marrow cell recruitment to form the premetastatic niche. Cancer Cell 15:35-44; 2009.

[16] Melillo, G. HIF-1: a target for cancer, ischemia and inflammation-too good to be true? Cell Cycle 3:154-155; 2004.

[17] Kaelin Jr., W. G. ROS: really involved in oxygen sensing. Cell Metab. 1:357-358; 2005.

[18] Klimova, T.; Chandel, N. S. Mitochondrial complex III regulates hypoxic activation of HIF. Cell Death Differ. 15:660-666; 2008.

[19] Lu, H.; Dalgard, C. L.; Mohyeldin, A.; McFate, T.; Tait, A. S.; Verma, A. Reversible inactivation of HIF-1 prolyl hydroxylases allows cell metabolism to control basal HIF-1. J. Biol. Chem. 280:41928-41939; 2005.

[20] Gao, P.; Zhang, H.; Dinavahi, R.; Li, F.; Xiang, Y.; Raman, V., et al. HIF-dependent antitumorigenic effect of antioxidants in vivo. Cancer Cell 12:230-238; 2007.

[21] Victor, N.; Ivy, A.; Jiang, B. H.; Agani, F. H. Involvement of HIF-1 in invasion of Mum2B uveal melanoma cells. Clin. Exp. Metastasis 23:87-96; 2006.

[22] Chang, S. H.; Worley, L. A.; Onken, M. D.; Harbour, J. W. Prognostic biomarkers in uveal melanoma: evidence for a stem cell-like phenotype associated with metastasis. Melanoma Res. 18:191-200; 2008.

[23] Qi, J.; Nakayama, K.; Gaitonde, S.; Goydos, J. S.; Krajewski, S.; Eroshkin, A., et al. The ubiquitin ligase Siah2 regulates tumorigenesis and metastasis by HIF-dependent and -independent pathways. Proc. Natl Acad. Sci. U. S. A. 105:16713-16718; 2008.

[24] Valencak, J.; Kittler, H.; Schmid, K.; Schreiber, M.; Raderer, M.; GonzalezInchaurraga, M., et al. Prognostic relevance of hypoxia inducible factor-1alpha expression in patients with melanoma. Clin. Exp. Dermatol. 34:e962-e964; 2009

[25] Sun, B.; Zhang, D.; Zhang, S.; Zhang, W.; Guo, H.; Zhao, X. Hypoxia influences vasculogenic mimicry channel formation and tumor invasion-related protein expression in melanoma. Cancer Lett. 249:188-197; 2007.

[26] Chiarugi, P.; Pani, G.; Giannoni, E.; Taddei, L.; Colavitti, R.; Raugei, G., et al. Reactive oxygen species as essential mediators of cell adhesion: the oxidative inhibition of a FAK tyrosine phosphatase is required for cell adhesion. J. Cell Biol. 161:933-944; 2003.

[27] van de Wetering, M.; Oving, I.; Muncan, V.; Pon Fong, M. T.; Brantjes, H.; van, L. D., et al. Specific inhibition of gene expression using a stably integrated, inducible small-interfering-RNA vector. EMBO Rep. 4:609-615; 2003.

[28] Shinomiya, N.; Gao, C. F.; Xie, Q.; Gustafson, M.; Waters, D. J.; Zhang, Y. W., et al. RNA interference reveals that ligand-independent Met activity is required for tumor cell signaling and survival. Cancer Res. 64:7962-7970; 2004.

[29] Taulli, R.; Accornero, P.; Follenzi, A.; Mangano, T.; Morotti, A.; Scuoppo, C., et al. RNAi technology and lentiviral delivery as a powerful tool to suppress Tpr-Met-mediated tumorigenesis. Cancer Gene Ther. 12:456-463; 2005.

[30] Dome, B.; Hendrix, M. J.; Paku, S.; Tovari, J.; Timar, J. Alternative vascularization mechanisms in cancer: pathology and therapeutic implications. Am. J. Pathol. 170: $1-15 ; 2007$

[31] Hendrix, M. J.; Seftor, E. A.; Hess, A. R.; Seftor, R. E. Vasculogenic mimicry and tumour-cell plasticity: lessons from melanoma. Nat. Rev. Cancer 3:411-421; 2003.

[32] Boccaccio, C.; Comoglio, P. M. Invasive growth: a MET-driven genetic programme for cancer and stem cells. Nat. Rev. Cancer 6:637-645; 2006.

[33] Corso, S.; Migliore, C.; Ghiso, E.; De, R. G.; Comoglio, P. M.; Giordano, S. Silencing the MET oncogene leads to regression of experimental tumors and metastases. Oncogene 27:684-693; 2008 .

[34] Comoglio, P. M.; Giordano, S.; Trusolino, L. Drug development of MET inhibitors: targeting oncogene addiction and expedience. Nat. Rev. Drug Discov. 7:504-516; 2008.

Fig. 6. Lung colonization assay. (A) After silencing of Rieske protein or Met kinase, $1 \times 10^{6} \mathrm{Hs} 294 \mathrm{~T}$ cells were incubated for $24 \mathrm{~h}$ under hypoxia and then injected into the lateral tail vein of SCID bg/bg mice. After 4 weeks the animals were sacrificed and lungs were examined. The means \pm SD of surface lung nodules are shown in the bar graph. ${ }^{*} P<0.005$ versus untreated under hypoxia. (B) $2 \times 10^{6} \mathrm{Hs} 294 \mathrm{~T}$ cells were pretreated for $1 \mathrm{~h}$ with $20 \mathrm{mM} \mathrm{NAC}, 1 \mu \mathrm{M}$ rotenone, or $150 \mathrm{nM}$ PHA or transfected with siRNA targeting HIF-1 $\alpha$; incubated for $24 \mathrm{~h}$ under hypoxia; and then injected into the lateral tail vein of SCID bg/bg mice. After 6 weeks the animals were sacrificed and lungs were weighed. Means \pm SD are shown in the bar graph. The horizontal line represents the weight of a healthy lung to allow estimation of total lung tumor differences among animal groups. ${ }^{*} P<0.005$ versus untreated under hypoxia. (C) Lung histological sections stained with H\&E (original magnification 20×; a 40× original magnification of a metastatic region is shown in the box). Micrometastasis are characterized by atypical large replicating malignant melanocytes disrupting lung alveoli. (D) Lung histological sections stained with laminin (original magnification 40x). In the box: strong laminin immunoreactivity found in hypoxic tumor cells is associated with red blood cell-containing channels, which are not lined by endothelial cells (original magnification 60x). Laminin immunoreactivity and red blood cell (RBCs) channel quantification is reported below. 
[35] Seftor, R. E.; Seftor, E. A.; Koshikawa, N.; Meltzer, P. S.; Gardner, L. M.; Bilban, M., et al. Cooperative interactions of laminin 5 gamma 2 chain, matrix metalloproteinase-2, and membrane type-1-matrix/metalloproteinase are required for mimicry of embryonic vasculogenesis by aggressive melanoma. Cancer Res. 61:6322-6327; 2001.

[36] Maniotis, A. J.; Folberg, R.; Hess, A.; Seftor, E. A.; Gardner, L. M.; Pe'er, J., et al. Vascular channel formation by human melanoma cells in vivo and in vitro: vasculogenic mimicry. Am. J. Pathol. 155:739-752; 1999.

[37] Storz, P. Reactive oxygen species in tumor progression. Front. Biosci. 10:1881-1896; 2005.

[38] Wu, W. S. The signaling mechanism of ROS in tumor progression. Cancer Metastasis Rev. 25:695-705; 2006.

[39] Chiarugi, P.; Giannoni, E. Anchorage-dependent cell growth: tyrosine kinases and phosphatases meet redox regulation. Antioxid. Redox Signal. 7:578-592; 2005.

[40] Ushio-Fukai, M. Redox signaling in angiogenesis: role of NADPH oxidase. Cardiovasc. Res. 71:226-235; 2006.

[41] Snyder, C. M.; Chandel, N. S. Mitochondrial regulation of cell survival and death during low-oxygen conditions. Antioxid. Redox Signal. 11:2673-2683; 2009.

[42] Radisky, D. C.; Levy, D. D.; Littlepage, L. E.; Liu, H.; Nelson, C. M.; Fata, J. E., et al. Rac1b and reactive oxygen species mediate MMP-3-induced EMT and genomic instability. Nature 436:123-127; 2005.

[43] Ferraro, D.; Corso, S.; Fasano, E.; Panieri, E.; Santangelo, R.; Borrello, S., et al. Prometastatic signaling by c-Met through RAC-1 and reactive oxygen species (ROS). Oncogene 25:3689-3698; 2006.

[44] Cannito, S.; Novo, E.; Compagnone, A.; Valfre, D. B.; Busletta, C.; Zamara, E., et al. Redox mechanisms switch on hypoxia-dependent epithelial-mesenchymal transition in cancer cells. Carcinogenesis 29:2267-2278; 2008.
[45] Yang, M. H.; Wu, M. Z.; Chiou, S. H.; Chen, P. M.; Chang, S. Y.; Liu, C. J., et al. Direct regulation of TWIST by HIF-1alpha promotes metastasis. Nat. Cell Biol. 10:295-305: 2008.

[46] Guzy, R. D.; Hoyos, B.; Robin, E.; Chen, H.; Liu, L.; Mansfield, K. D., et al. Mitochondrial complex III is required for hypoxia-induced ROS production and cellular oxygen sensing. Cell Metab. 1:401-408; 2005.

[47] Ishikawa, K.; Takenaga, K.; Akimoto, M.; Koshikawa, N.; Yamaguchi, A.; Imanishi, H. et al. ROS-generating mitochondrial DNA mutations can regulate tumor cell metastasis. Science 320:661-664; 2008.

[48] Wang, F. S.; Wang, C. J.; Chen, Y. J.; Chang, P. R.; Huang, Y. T.; Sun, Y. C., et al. Ras induction of superoxide activates ERK-dependent angiogenic transcription factor HIF-1alpha and VEGF-A expression in shock wave-stimulated osteoblasts. J. Biol Chem. 279:10331-10337; 2004.

[49] Graeber, T. G.; Osmanian, C.; Jacks, T.; Housman, D. E.; Koch, C. J.; Lowe, S. W., et al. Hypoxia-mediated selection of cells with diminished apoptotic potential in solid tumours. Nature 379:88-91; 1996.

[50] Hammond, E. M.; Kaufmann, M. R.; Giaccia, A. J. Oxygen sensing and the DNAdamage response. Curr. Opin. Cell Biol. 19:680-684; 2007.

[51] Pani, G.; Giannoni, E.; Galeotti, T.; Chiarugi, P. Redox-based escape mechanism from death: the cancer lesson. Antioxid. Redox Signal. 11:2791-2806; 2009.

[52] Calvani, M.; Trisciuoglio, D.; Bergamaschi, C.; Shoemaker, R. H.; Melillo, G. Differential involvement of vascular endothelial growth factor in the survival of hypoxic colon cancer cells. Cancer Res. 68:285-291; 2008.

[53] Lluis, J. M.; Buricchi, F.; Chiarugi, P.; Morales, A.; Fernandez-Checa, J. C. Dual role of mitochondrial reactive oxygen species in hypoxia signaling: activation of nuclear factor-kB via c-SRC and oxidant-dependent cell death. Cancer Res. 67:7368-7377; 2007. 